\title{
Flipping the Script: Master-Student to Student-Masters
}

\author{
GREGORY THOMAS SPAW \\ American University of Sharjah
}

This paper presents the particular challenges of teaching a North-American model of education outside the US. The challenges take place in a remarkably diverse institution where international students represent $84 \%$ of enrollees and woman represent more than $80 \%$ of the Department of Architecture's students. ${ }^{1}$

With such unique backgrounds and experiences, one would imagine our classrooms would inherently be engulfed with differing perspectives and opinions, but unfortunately this is not the case. Oftentimes, the prevalence of rote learning and previously established master-student dynamics in primary and secondary educations have hampered the students' propensity to speak freely and articulate critical thinking. ${ }^{2}$ The challenge, then, is to help them unlearn past habits while pushing our undergraduates to become masters of their own environment, education, and design language.

An assortment of studio experiences will be presented with corresponding student work to demonstrate these challenges. The associated assessment evidence successes and failures of these evolving and adaptable pedagogical strategies. The aim of this paper is to explore active ways of preparing the next generation of student-masters globally.

\section{STUDENT-MASTERS_ENVIRONMENT}

For students to become masters of their own environment, they must find their voice and have the confidence to use it. Within a western context, it is hard to imagine students not arriving with both qualities in spades, but due to the particulars of the gulf region, one cannot take such things for granted. As educators we must reinforce our students' willingness to participate by creating safe spaces for dialog as well as purposefully redirecting close ended questions with open-ended prompts such as, "I don't know-what do you think?" Initially the students are often perplexed by this response, with some taking the statement at face value before sheepishly smiling; With time though they realize that the onus is on them to formulate and support their own ideas. Patience and a touch of humor goes a long way during these moments of discombobulation. Over the course of a semester, the repetition of this type of exchange solidifies for the vast majority of students the marked differences between rote learning and the more active learning appropriate to an architectural education.
An additional challenge within the unique educational environment of the United Arab Emirates is mediating gendered cultural expectations with the need for students to "lean in" in order to have success in future practice. While one needs to be conscious of unintentionally imposing American values/ mannerisms, the challenges on the ground have on occasion dictated that I feign hearing loss in order to force students to speak up and engage their classmates with conviction.

Another way to support students in becoming masters of their environment is through the physical shaping of spaces for discussion and curation of critic. At the American University of Sharjah the second and third years of the architecture studio sequence are coordinated, with the former being cooperative across multiple studio sections. The gathering, instruction, discussion, and review among the whole second year cohort pushes individuals to actively listen, mentally engage, and verbally participate, all while considering the relationship of their own work to the broader context of student and faculty dialog. Typically, these activities are done in a large flexible space that accommodates presentations, pinups, and informal debates. ${ }^{3}$

Traditional rowed seating allows for collective observation with attention directed toward a presentation or speaker, but such a spatial set-up reinforces power dynamics antithetical to students being comfortable in finding their voice. This particular organization also works poorly when trying to discuss specific pinned up examples of student work with large groups. Keeping students tuned in is nearly impossible, though the conversation might be relevant to their own work, if they cannot see the project in question. A clever workaround to overcome and better engage the students came in the form of ordinary post-it notes and a digital camera. Using these two items, an informal pin-up could transition from a series of peer to peer exchanges to a collective discussion across the whole of the second-year class. Armed with these day glow stickies, the students can tag and comment to raise issues or praise their peer's work. After a few minutes, notable areas of interest emerge and are documented with the camera. In another five minutes the photographed work can be projected for all to easily observe and discuss. Perhaps the darkened room eases inhibitions or it is simply the ability for all to see, but through this technique the quantity and quality of commentary from the students markedly improves. 


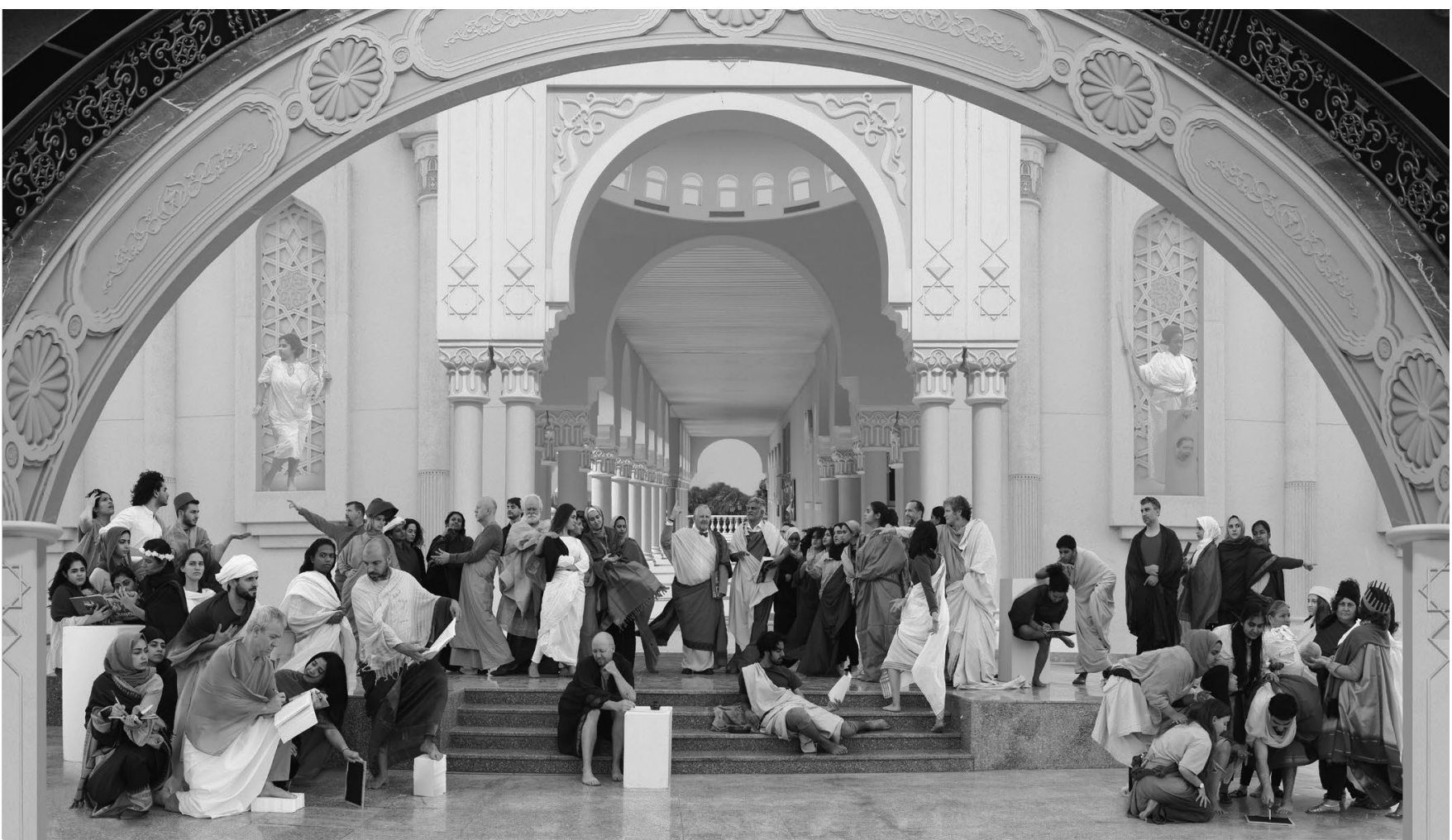

Figure 1. School of Athens Reenacted | Students and Faculty of AUS, Divya Mahadevan, Farah Monib, Gopika Praveen, Nabeela Zeitoun, Tasnim Tinawi, Zahra'a Nasralla and Uthra Varghese.

Building from this approach and as an effort to counter previous spatial hierarchies the students likely experienced throughout their foundational educations, other seating configurations have been employed as well. The ubiquitous seating in the round has made collective conversations more egalitarian, though priming the student led exchanges requires liberal use of the Socratic method and the patience and discipline amongst the instructors to hang back and let the students take the lead.

One of the more interesting organizational arrangements of the flexible space came as a byproduct of the vocalized differences in opinions among the collective instructors of the coordinated studio. The organic jousting in front of the students proved useful in several ways. First it communicated to the students a multitude of viable approaches to a particular issue or subject, while never giving them the "right" answer. Second, it forced them to start finding ways of understanding and projecting their own architectural discourse. Indeed, on one occasion during a particularly intense site analysis postmortem, the students organized themselves in two camps facing one another with several tables dividing them. Taking turns, the students used examples of their work to debate the merits of their differing approaches. While no clear consensus was reached, the students through the self-initiated exercise demonstrated a moment of mastery of their learning environment.

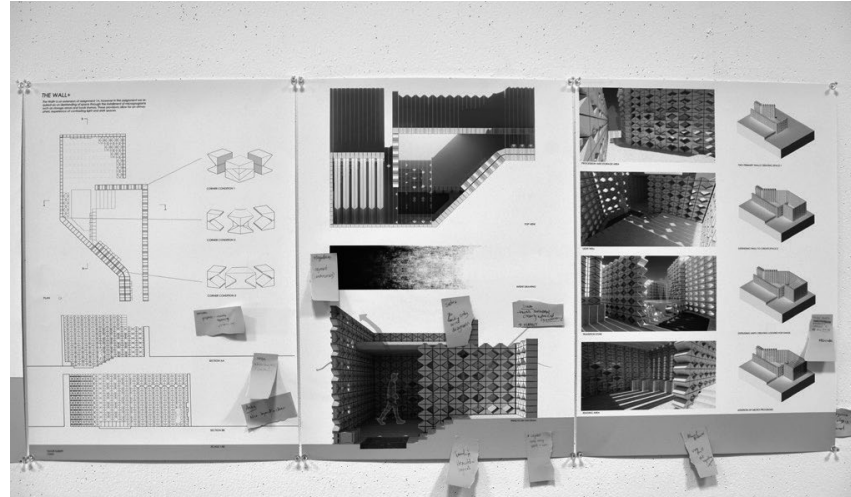

Figure 2. Project from Post-it Review, Nour Elbery.

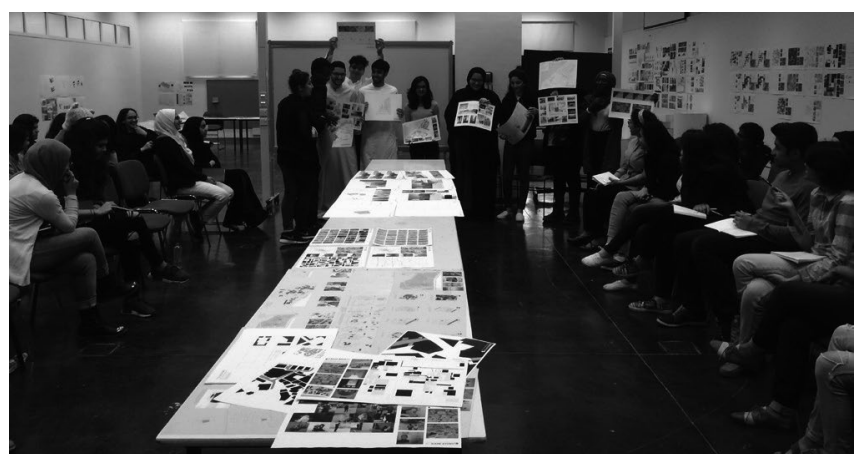

Figure 3. The Great Debate. 


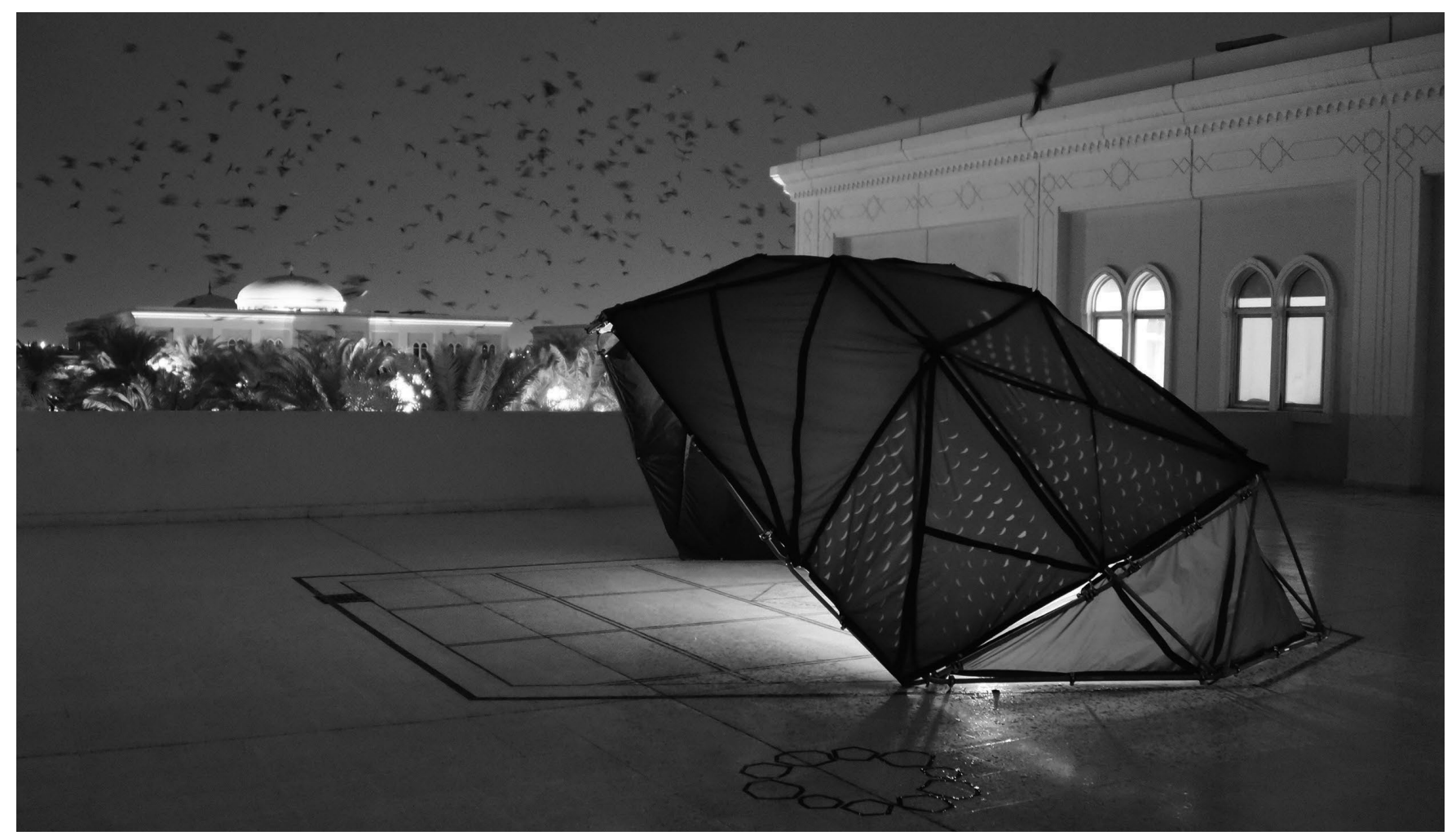

Figure 4: Neonomads Shelter Prototype Deployed for Final Review, Afra Galadari, Azmiha Raza, Bana Mansour, Basil Al Taher, Divya Mahadevan, Farah Monib, Gopika Praveen, Misbah Shehreen Baig, Moza Al Mheiri, Nermin Hegazy, Omaima Al Ansari, Sarah Al Maddah, Shahd Abdulghani, Yasmin Abdelrehim, and Zahra'a Nasralla.

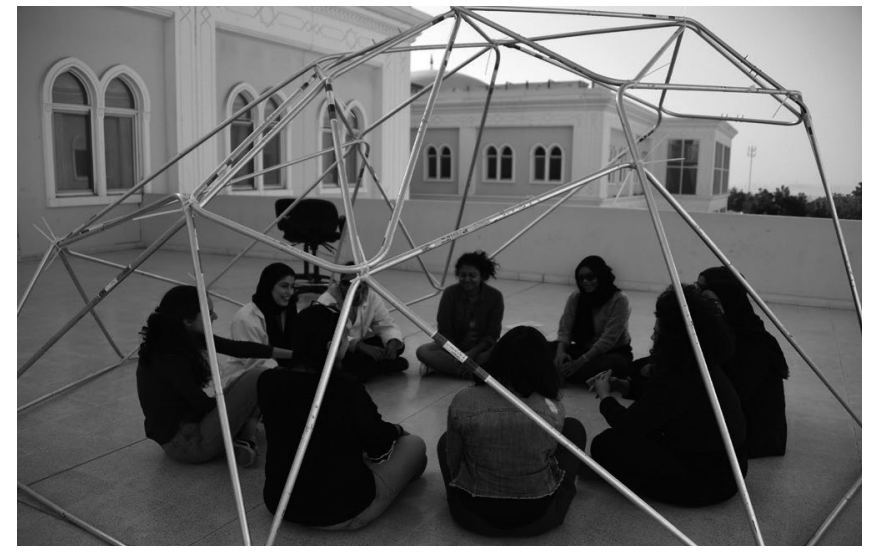

Figure 5: Neonomads Shelter Prototype Test Fit with Team.

\section{STUDENT-MASTERS_EDUCATION}

To be masters of their own education, students must be willing to employ self-determination and agency in their pursuit of learning. For these traits to be developed, it often requires teachers to consciously hold back and allow students to drive discussions. Additionally it is important to regularly call on students to propose their own deliverables in order to actively engage them, which, in turn promotes accountability. Through the structure of courses and required presentations/ demonstrations, we can facilitate opportunities for students to become educational curators, thus encouraging them to teach and learn from one another.

In the fall of 2017, Professor Patrick Rhodes and myself were selected to teach a yearlong design build options studio to 4th and 5th year undergraduate students. Entitled Neonomads, the impetus for the studio was a fascination with the extreme conditions of the Rub' Al Khali or Empty Quarter, with its 255,000 square miles of continuous sand desert. ${ }^{4}$ While the AUS department of architecture has had a number of successful architectural and interior design build projects, the proposed construct would be the first sited off campus within the daunting environmental conditions of the Arabian Desert.

To make the situation even more unusual, "We began the project with no site, no client, and no community partner." ${ }^{\prime 5}$ Initially this meant that while the students were being introduced to the challenges to come through an introductory exercise, research, and preliminary design, behind the scenes my colleague and I were scurrying to find a client with access to an appropriate site. While the students were still able to design with generalized conditions in mind, it did not take too long for them to get wise to the realities of our circumstance. In hindsight, what seemed less than ideal may very well have been the catalyst that pushed the students toward greater agency 

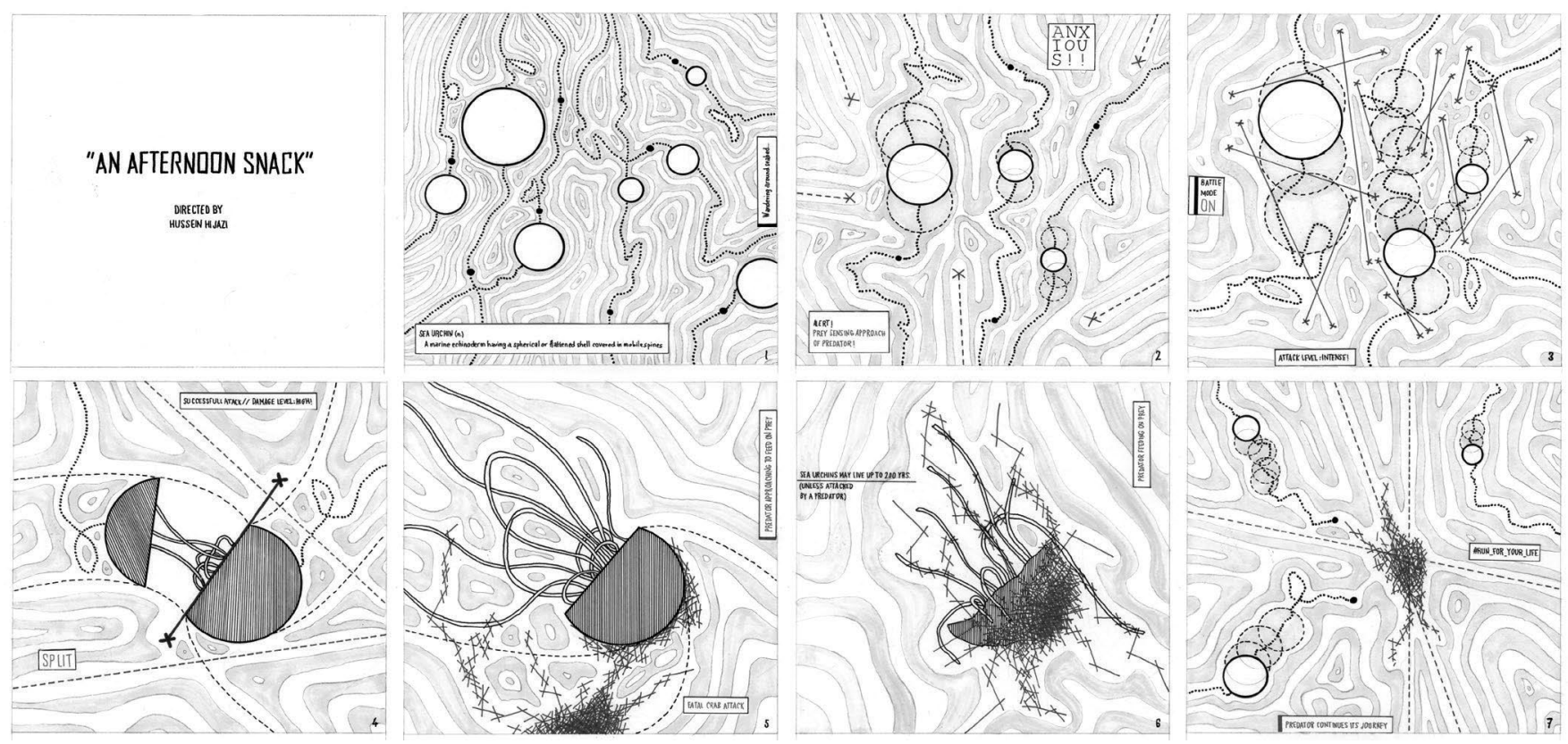

Figure 6: Fight or Flight: Models for Design Phase 1, Hussein Hijazi.

and responsibility in their educational experience. In practical terms the hardship of being without a specific site meant that adjustments to the course schedule needed to be made, but by treating the students more like peers working toward a common goal, there was an understanding that we were in this together. It was about half way through the semester during studio meetings and pinups that I started to consciously hold back to let the students take a more pronounced lead of the project's development. My new found "fly on the wall" status was initially met with some sceptism, but through the selective interjection of critical questions at timely moments the students grew more comfortable with their collective decision making.

Finally, around week twelve after meeting with the Sheikh's architect, Peter Jackson, and being introduced to two environmental scientists, John Pereira and Brendan Whittington-Jones, from the Sharjah Environment and Protected Areas Authority, we were offered a potential site in rugged mountains of Wadil Helo to shelter herpetologists during their overnight field study. ${ }^{6}$ The students presented the work that had been completed thus far, and with only three and half weeks before the end of the semester, collectively decided to an ambitious goal of constructing a 1:1 prototype using a previously developed interweaving of aluminum loops. The demands the students put on themselves were considerable but working collectively they agilely organized themselves in the design, fabrication, finishing, assembly, and presentation, resulting in an impressive effort and output displayed at the final review. Perhaps most importantly, the students through the course of the semester became curators of their own educational experience.

\section{STUDENT-MASTERS_DESIGN LANGUAGE}

For students to become masters of their own design language, we as academics must put our egos and self-interest aside. Their designs are not, nor should they be, about our personal agendas. We need to foster students by giving them both the space and time to discover, develop, and articulate their own interests and languages of design.

A year after my experience teaching the Neonomads design build, I was offered the opportunity to teach a fifth-year option studio of my own accord. Like other young faculty, it is tempting to see these as opportunities to pursue our own personal agendas. In fact the academic system is built to incentivize us to leverage our teaching toward our own creative and scholarly pursuits. This is not to say that we do not have knowledge, experience and skills to share with our students but especially when teaching undergraduates, our interest may not align with what they really need at that moment in time.

When considering what topic to pursue, it was hard not to notice that, while the students at the school had built plenty of physical models of the previous semesters, it was generally a pained exercise begrudgingly completed as a requirement rather than a worthwhile avenue toward considered study of a particular architectural query. With this in mind, it only seemed appropriate to build into the studio premise a healthy dose on "doing the things we don't want to do" along with the studio's flashier mode of exploration.

Titled Fight or Flight: Models for Design, the point of inception of the studio was representation of natural strategies for survival such as camouflage, flocking, and diversion. While 


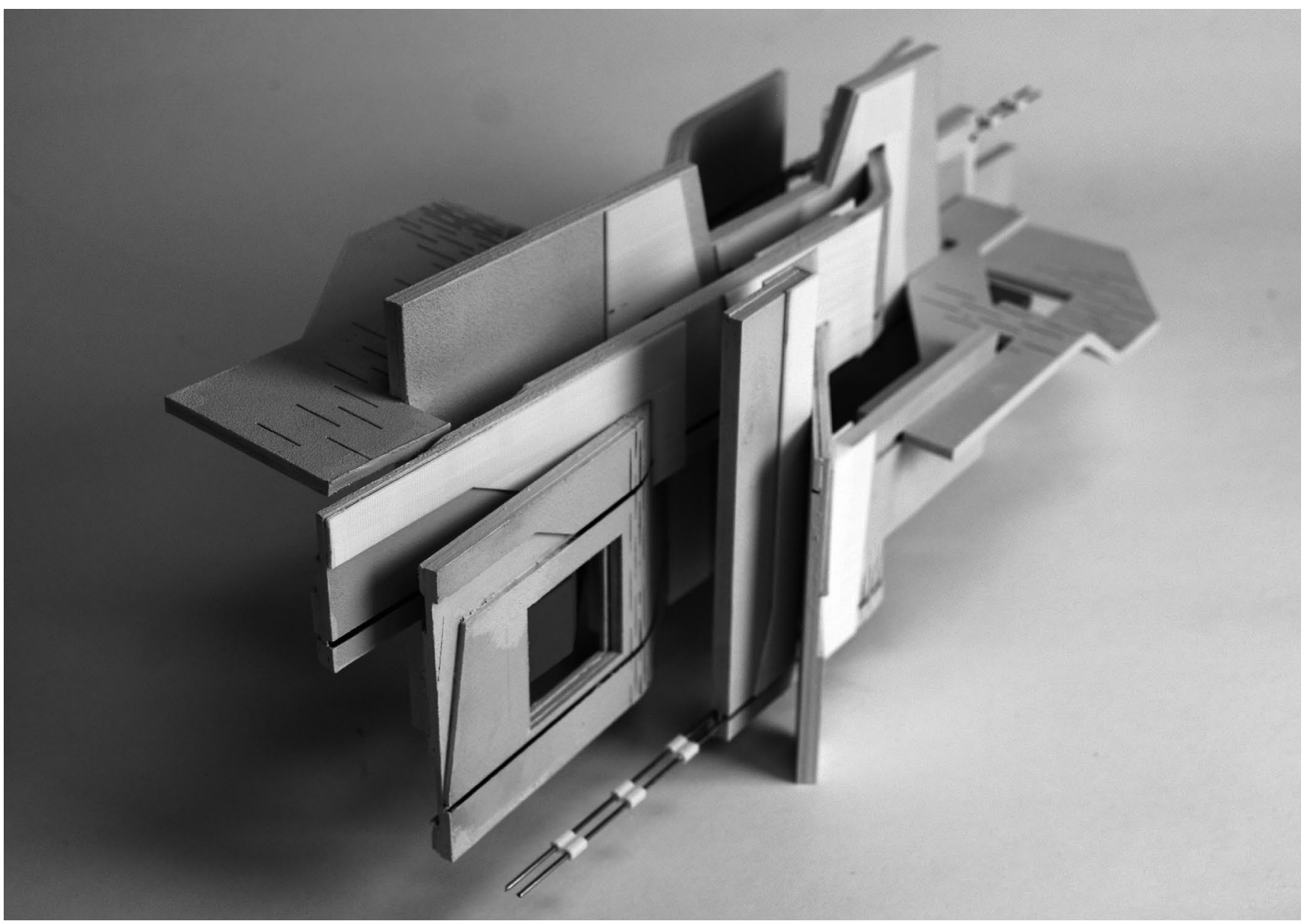

Figure 7: Fight or Flight: Models for Design Phase 2, Nohair Elmessalami.

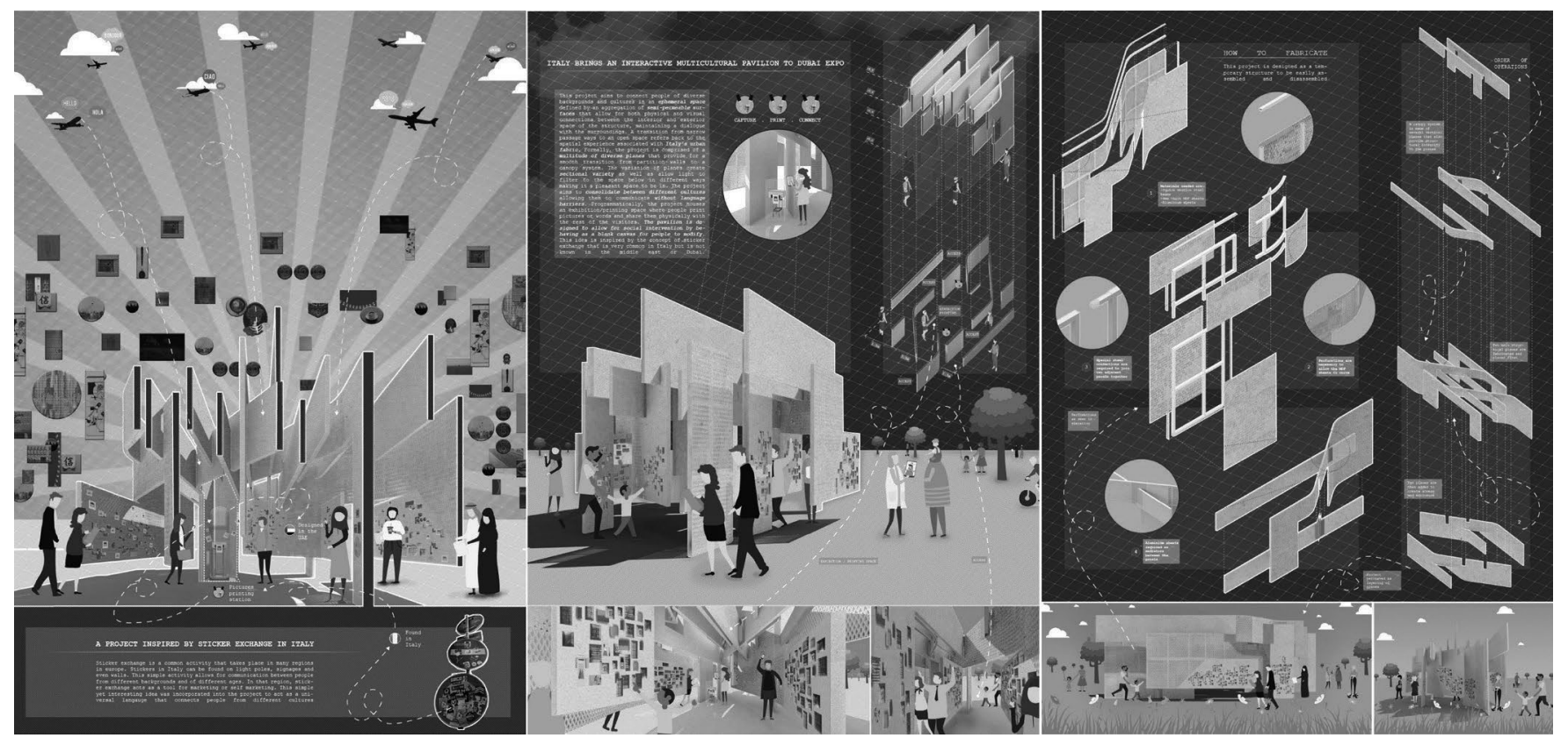

Figure 8: Fight or Flight: Models for Design Phase 3 | Awarded Submission for the Connecting Spaces Competition, Nohair Elmessalami. 


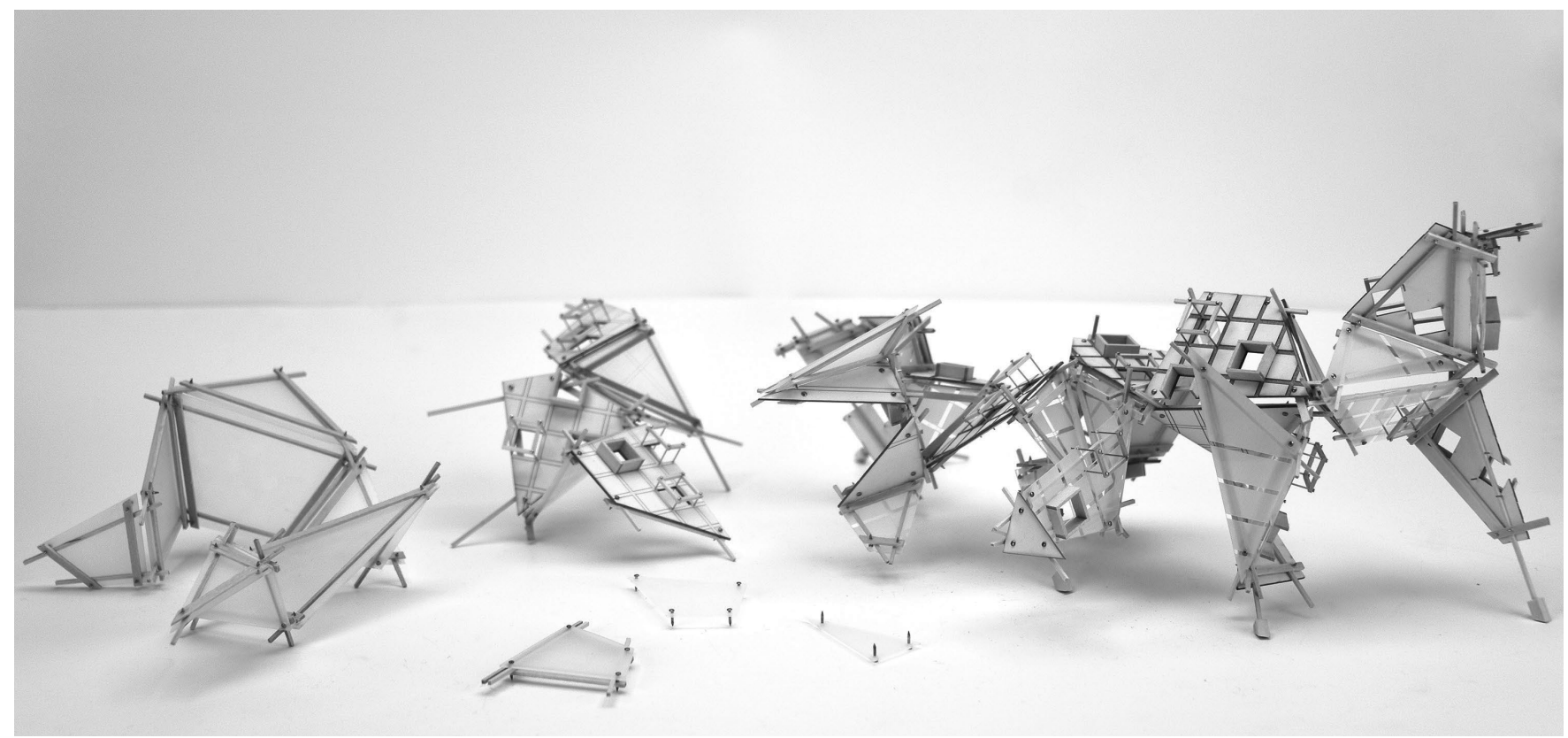

Figure 9: Fight or Flight: Models for Design Phase 2, Sondos AlSibai.

the students spent two weeks iterating and creating compelling notational systems to represent the reciprocity of their predator $v$. prey relationships, the premise of the exercise was a McGuffin toward the greater pursuit of having the students develop a unique design language. This phase also introduced key criteria of precision, craft, and rigor by which the students' work would be evaluated throughout the semester.

For the second phase, the students were tasked with shifting their unique personal language from two dimensions of space and the dimension of time to harnessing the three dimensions of physical space. Taking nearly half the semester, the goal was to translate and iterate through a sequence of tangible models the interplay of disparate actors, elements, and materials across a series of scales. As students soon-to-be graduating, the intent was to give them something they would find far rarer within a work setting. The luxury of time, not to do nothing, but to pursue their own visions. With plenty of freedom, the desk critics were opportunities to ask critical questions in support of the development of their own physical studies. For the mid-review, a salon style was employed allowing 1:1 feedback from a group of outside reviewers in an informal setting that emphasized relevant feedback and allowed discussion to take the time that was really needed. By the end of the second phase the students had developed a body of diverse approaches and were far more comfortable in their ability to meaningfully iterate their architectural intent through physical modeling as a primary design driver.

Building from their previous efforts, the final five weeks was dedicated to producing submissions for, Connecting Spaces, and architectural competition for Expo 2020 sponsored by the Lombardy Region and the Milan Chamber of Commerce. Due to the competition framework being quite broad, the vast majority of the students were able to pivot and carry forward threads from their previous studies. Of the projects eventually submitted, three were selected for prizes of 20,000 euros for use toward development and fabrication with the work to be showcased in Milan and at the forthcoming Expo 2020 in Dubai.

\section{CONCLUSIONS}

Whether we are preparing our students to be masters of their environment, education, or design language, we are inherently creating opportunities for them to find and hone their voice. Strangely and somewhat counterintuitive to our job description, to help our students find their voices, we often need to use ours less. The vacuum that we leave, while uncomfortable at times, cultivates awareness, contemplation, and critique in our student-masters in training.

\section{ENDNOTES}

1. "International Student Table 2018: Top 200 Universities," Times Higher Education, May 16, 2018, publication, https:// www.timeshighereducation.com/student/best-universities/ international-student-table-2018-top-200-universities\#survey-answer

2. Richard Edwards and Robin Usher, Globalisation \& Pedagogy: Space, Place and Identity. (London: Routledge, 2008), 54.

3. For more on Active Learning, see C Carney Strange and James H Banning, Designing for Learning: Creating Campus Environments for Student Success. (John Wiley \& Sons, 2015), 28.

4. H. Stewart Edgell, Arabian deserts: nature, origin, and evolution. (Springer Science \& Business Media, 2006), 127.

5. Patrick Rhodes and Gregory Thomas Spaw, "Neonomads: between education and practice," in Proceedings of 2019 ACSA/EAAE Teachers Conference, ed. Johan De Walsche and Richard Blythe (Antwerp: University of Antwerp, 2019), forthcoming.

6. "Wadil Helo," Environment and Protected Areas Authority, November 10, 2019, access, http://www.epaashj.ae/protected-areas/wadil-helo/. 